\title{
Research on the New Retail Business Model from the Financial Perspective
}

\section{Huijuan Wu Yang Yang Hongfei Sun Jiahua Liu}

School of Economics and Management Northeast Dianli University Jilin Jilin 132012

\begin{abstract}
Through the construction of the business model canvas, the new retail business model is financially analyzed, and based on this, it is concluded that there are still some shortcomings in the implementation of the new retail business model. At the end of this article, the corresponding flaws in the performance of the new retail business model are proposed. There are suggestions for improvement.
\end{abstract}

Keywords: New Retail; Business Model; Financial Analysis; Business Model Canvas

Fund project: 1 The "13th Five- Year" Scientific Research Planning Project of the Education Department of Jilin Province (Social Science Research Project) "Research on Multi-Source Fusion Personalized MicroReading User Portrait Model Based on User Cognition" (JJKH20190715SK).

2 The General Project of Higher Education Scientific Research of Jilin Provincial Higher Education Association "Research on Influencing Factors and Promotion Strategies of Online Classroom Teaching in Colleges and Universities" (JGJX2020D93).

3 The "13th Five-Year" Scientific Research Planning Project of the Education Department of Jilin Province (Social Science Research Project) "Research on the Construction Model and Influence Improvement Path of Jilin Province's New Type of University Think Tanks" (JJKH20180459SK).

DOI : 10.36012 /ems. v2i1. 2792

\section{Introduction}

\section{1 Research background}

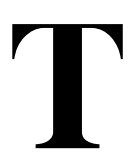

he national reform and opening policy has driven the rapid development of China's economy, which has also changed consumer demand and intensified competition in the retail market. Jack $\mathrm{Ma}$, the founder of the Alibaba Group, officially held the Computing Conference 2016 in Yunqi Town, Hangzhou, on October 13, 2016. Putting forward the concept of " new retail" has received widespread attention from society. In terms of domestic policies, in $\mathrm{No}^{-}$ vember 2016, the State Council issued its opinions on promoting the innovation and transformation of 
the physical retail industry. The opinions proposed to establish a social and market-oriented data application mechanism and encourage e-commerce platforms to conditionally open data to physical retail companies Resources and improve resource allocation efficiency and management decision making level ${ }^{[2]}$. Many factors have promoted the rapid development of China's retail format. The new retail format will soon become the main driving force for expanding China's retail industry ${ }^{[1]}$.

\section{2 Research significance}

\section{2.1 Theoretical significance}

The new retail business model has promoted the implementation of supply - side structural reforms. The new retail business model created a customer - oriented business model, which made up for the slow response of the traditional business model to the market, which is likely to cause unsalable products.

\section{2. 2 Practical significance}

(1) The development of new retail business models meets the growing demand for high-quality products

The new retail model makes full use of the advantages of each element in it and integrates and reorganizes market resources so that the development and promotion of corporate business models meet the needs of most consumers.

(2) New retail business models promote the transformation and upgrading of traditional business models

The new retail business model has constructed a diversified, intelligent, and convenient online and offline integrated innovative business model.

(3) The development of new retail business models integrates the two- way development of the traditional real economy and the new Internet environment.

The establishment of a new retail business model is to combine the offline real economy and online
Internet retail methods, integrate the advantages of both parties, complement each other, and carry out reasonable allocation of resources, thereby promoting the slow growth of China's national $\mathrm{e}^{-}$ conomy.

\section{3 Research content and methods}

Based on the business model element canvas model, this paper studies the relevant theoretical knowledge of new retail and business models and draws a new retail business model element canvas. Through the nine major elements of the business model canvas based on the financial perspective, the new retail business model is analyzed one by one. And use relevant financial data to calculate, evaluate the pros and cons of the new retail business model so as to provide suggestions for the drawbacks of the new retail.

This article uses literature review, case analysis, and comparative analysis to illustrate and analyze the new retail business model from the financial perspective.

\section{Financial Analysis of New Retail Business}

\section{Model}

\section{1 New retail business model model}

Based on the business model canvas first proposed by Alexander Osterwalder in 2005, this article will construct a business model canvas based on a financial perspective and roughly divide the business model canvas into nine elements. The nine elements are value proposition, investment capacity, financing capacity, operating capacity, cash capacity, debt solvency, economic value - added, cost structure, and income source. The above nine elements are the basis for forming a financial perspective business model canvas. On this basis, these nine elements can be classified into three major parts, namely value proposition, asset management (investment management, financing management, debt service management, operation management, cash management, and economic value 
added) and financial management ( cost structure, income source).

Based on the analysis of the above nine business model canvas elements, different financial indicators are formulated. The following is a financial analysis based on nine elements.

\section{2 Investment financial indicators}

The investment of an enterprise includes the investment inside the enterprise and the investment beyond the enterprise. The analysis of the investment indicators of an enterprise is to calculate the proportion of the above- mentioned investments in different directions in the total assets.

\section{3 Financing financial indicators}

There are two main types of corporate financing, one is debt financing, the other is equity financing, and an analysis of the financial indicators of a company's financing is to calculate the proportion of the above two types of financing in the total liabilities.

\section{4 Operating financial indicators}

The operating financial index is a reflection of the company's operating conditions and is an index for calculating the profits obtained by the company's operation of its inherent assets. It mainly calculates indicators such as total asset turnover rate, accounts receivable turnover rate, inventory turnover rate, and sales growth rate.

\section{5 Debt service financial indicators}

The financial indicator of solvency is an important indicator of corporate financial management, which refers to the ability of an enterprise to repay when due. Its leading financial indicators are current ratio, quick ratio, shareholders' equity ratio, asset-liability ratio.

\section{6 Economic value - added indicators}

The financial strategy matrix integrates the theory of sustainable growth and the theory of value creation. It uses the sales growth rate and the sustainable growth rate to divide the corporate strategic layout into four quadrants. Each quadrant represents a unique type of enterprise: the first quadrant. It is a value - added cash shortage, that is, $\mathrm{EVA}>0$, sales growth rate $>$ sustainable growth rate; companies in the first quadrant generally have a growth period. The second quadrant is value - added cash surplus, that is, $\mathrm{EVA}>0$, sales growth rate $<$ sustainable growth rate; companies in the second quadrant are generally in the mature period. The third quadrant is deductible cash surplus, that is, $\mathrm{EVA}<0$, sales growth rate $<$ sus $^{-}$ tainable growth rate; the characteristics of enterprises in the third quadrant are that they have surplus cash, but the enterprise itself has no ability to create value. The fourth quadrant is the detrimental cash shortage, $\mathrm{EVA}<0$, sales growth rate $>$ sustainable growth rate; the companies in the fourth quadrant are obviously in the recession period.

\section{Countermeasures}

Since the new retail business model was proposed in 2016 , it has been supported by many retail companies. Although there are many advantages for individual companies to implement the new retail business model, the broad application of the new retail model also highlights the shortcomings of the development of the new retail model. The following are suggestions based on the shortcomings highlighted in the implementation of new retail business models by enterprises in recent years:

(1) Create an omnichannel, borderless model to solve industrial logistics problems

Improve the integration of online, offline, and logistics to solve the shortcomings of the current new retail model. 1. Retail companies further expand offline physical stores, use the Internet of Things (IoT) and big data to distribute scientifically and reasonably in different regions, shorten the distance of logistics distribution and reduce waiting time. Second, the company actively ex- 
pands offline channels and promotes long - term strategic partnerships and joint cooperation with third - party logistics companies so that the goal of omnichannel and borderless new retail can be realized.

(2) Improve offline service satisfaction, improve online product details push, and improve corporate favorability

A good reputation will enable companies to gain more popularity among consumers. At present, most of the main consumers are the post $-80 \mathrm{~s}$ and post -90 s groups. With the fast - paced pace of life, these groups often choose retail stores randomly. A good reputation will often make companies appear first among most options.

(3) Ensure safe payment technology and improve the online payment environment

Consumers are paying more and more attention to protecting personal rights and information, and safeguarding consumers' own legal rights and protecting consumer information security is also a major issue that enterprises and the country must consider while continuing to develop new retail business models in the future. A safe protection mechanism needs to be created to ensure that consumer information leakage can be effectively prevented in the process of taking advantage of the convenience brought by new technologies and provide consumers with a safe shopping environment.
It requires progress made in terms of consumers, enterprises, and the country.

\section{Conclusion}

This article first analyzes the background and research significance of the new retail model. It confirms the research content of this article, using literature review, case analysis, and comparison to analyze the new retail business model from the financial perspective. Taking the business model canvas composed of nine elements proposed by $\mathrm{Al}-$ exander Osterwalder as a model, a new retail business model canvas from a financial perspective is constructed. And more systematic analysis of the nine elements of the new retail business model canvas. Finally, based on the introduction of new retail, it sorts out and summarizes the shortcomings of new retail and puts forward corresponding countermeasures and suggestions.

\section{References}

[1] Dong Cong. Research on consumer buying behavior orientation based on $\mathrm{e}^{-}$-commerce platform $[\mathrm{J}]$. Modern Marketing (late issue), 2019 (01): 62-62.

[2] Wang Mian, Huang Ying, Yang Ying. The path, experience and enlightenment of business model innovation under the Internet platform $[J]$. Science and Technology and Industry, 2019, 19 (04) : 92-98.

[3] Ma Lan. Research on the Impact of New Ventures Different Strategic Orientations on Business Model Innovation $[\mathrm{J}]$. Technoeconomics and Management $\mathrm{Re}^{-}$ search, 2019 (05): 62-67. 